\title{
Dietary sophorolipid accelerates growth by modulation of gut microbiota population and intestinal environments in broiler chickens
}

Min-Jin Kwak ${ }^{1 \dagger}$, Min-Young Park ${ }^{1 \dagger}$, Yong-Soon Choi ${ }^{1}$, Junghwan Cho ${ }^{1}$, Duleepa Pathiraja', Jonggun Kim', Hanbae Lee ${ }^{2}$ In-Geol Choi ${ }^{1}$ and Kwang-Youn Whang ${ }^{1 *}$

\begin{abstract}
Background: Gut is a crucial organ for the host's defense system due to its filtering action of the intestinal membrane from hazardous foreign substances. One strategy to strengthen the gut epithelial barrier function is to upregulate beneficial microflora populations and their metabolites. Sophorolipid (SPL), which is a glycolipid biosurfactant, could increase beneficial microflora and decrease pathogenic bacteria in the gastrointestinal tract. Therefore, herein, we conducted an experiment with broiler chickens to investigate the fortifying effects of SPL on the host's gut defense system by modulating the microbiota population.

Methods: A total of 540 1-day-old chicks (Ross 308) were used, and they were immediately allotted into three treatment groups (6 replications with 30 chicks/pen) according to their initial body weight. The dietary treatments consisted of CON (basal diet), BAM (10 mg/kg bambermycin), and SPL (10 mg/kg SPL). During the experiment, birds freely accessed feed and water, and body weight and feed intake were measured at the end of each phase. On d 35, birds (one bird/pen) were sacrificed to collect jejunum and cecum samples.

Results: Dietary SPL and BAM supplementation significantly accelerated birds' growth and also significantly improved feed efficiency compared to CON. Intestinal microbial community was significantly separated by dietary SPL supplementation from that of CON, and dietary SPL supplementation significantly increased Lactobacillus spp. and Akkermansia muciniphila. Moreover, birds fed with dietary SPL also showed the highest concentration of cecal butyrate among all treatment groups. Gut morphological analysis showed that dietary SPL significantly increased villus height, ratio of villus height to crypt depth, goblet cell numbers, and the gene expression levels of claudin-1 and mucin 2. Additionally, dietary SPL significantly decreased the mRNA expression level of pro-inflammatory cytokine, interleukin-6, and increased that of anti-inflammatory cytokine, interleukin-10, compared to other treatments.
\end{abstract}

\footnotetext{
* Correspondence: kwhang@korea.ac.kr

${ }^{\dagger}$ Min-Jin Kwak and Min-Young Park contributed equally to this work.

${ }^{1}$ Department of Biotechnology, Korea University, 145 Anam-ro, Seoul 02841, Republic of Korea

Full list of author information is available at the end of the article
}

(c) The Author(s). 2021 Open Access This article is licensed under a Creative Commons Attribution 4.0 International License, which permits use, sharing, adaptation, distribution and reproduction in any medium or format, as long as you give appropriate credit to the original author(s) and the source, provide a link to the Creative Commons licence, and indicate if changes were made. The images or other third party material in this article are included in the article's Creative Commons licence, unless indicated otherwise in a credit line to the material. If material is not included in the article's Creative Commons licence and your intended use is not permitted by statutory regulation or exceeds the permitted use, you will need to obtain permission directly from the copyright holder. To view a copy of this licence, visit http://creativecommons.org/licenses/by/4.0/ The Creative Commons Public Domain Dedication waiver (http://creativecommons.org/publicdomain/zero/1.0/) applies to the data made available in this article, unless otherwise stated in a credit line to the data. 
Conclusions: Dietary SPL increases the beneficial bacterial population and butyrate concentration, which leads to a strengthened gut barrier function. In addition, the intestinal inflammation was also downregulated by dietary SPL supplementation.

Keywords: Broilers, Gut microbiota, Gut morphology, Local inflammation, Mucus barrier, Sophorolipids

\section{Introduction}

In the livestock industry, antibiotics have been widely used as growth promoters with sub-therapeutic dosage due to their outstanding efficacy in feed conversion and animal growth [1]. Nonetheless, the use of antibiotic growth promoters has been banned because the livestock fed with antibiotic growth promoter could serve as a reservoir of antibiotic-resistant bacteria [2]. Hence, it could threaten human life by transmitting antibioticresistant bacteria to humans by direct animal contact or indirect environmental contact [3].

Consequently, the development of novel and ecofriendly materials (e.g., probiotics, prebiotics, organic acids, essential oils, and enzymes) to replace antibiotic growth promoters is needed [4]. Additionally, various bio-surfactants have been investigated because of their antibacterial property [5]. Among bio-surfactants, sophorolipid (SPL) has received much attention in various industrial fields, such as medical, hygiene, and pharmaco-dermatological areas, due to their relatively less toxicity and more biodegradability [6].

SPL is a glycolipid-type amphiphilic compound similar to bambermycin, and it is produced by non-pathogenic yeast species, including Candida bombicola [7]. It consists of a nonpolar fatty acid tail of 16 or 18 carbon atoms and a polar dimetric carbohydrate head, which is linked by a glycosidic bond and binding of non-polar fatty acid and polar carbohydrate determines structure of SPL, acidic and lactonic forms [8]. Both forms of SPL are able to be produced by Candida bombicola, and they exert diverse biological properties according to their forms [9]. In acidic form, SPL shows high solubility with foam-forming ability by its higher esterification capacity, however, lactonic form of SPL exhibits better surface tension reducing activity and biological activity [10].

Collectively, SPL exerts diverse biological properties, including antibacterial activity, immunomodulation capacity, and stimulation of dermal fibroblasts and collagen production, $[11,12]$. These properties imply that SPL has a potential to be applied in the animal feed industry for improving animal health and growth however, there are few reports on the application of this compound in this field. Hence, we conducted an experiment to evaluate the efficacy of SPL on gut microbial population and their metabolites could lead to improvement of growth performance in in broiler chickens.

\section{Materials and methods}

We conducted all of the studies on the birds in accordance with the guidelines and regulations of the Animal Ethics Committee approved by Korea University (Seoul, Republic of Korea), and it was carried out at a research farm in Cheonan, Republic of Korea (Approval number: KUIACUC-2020-0097).

\section{Birds and diets}

A total of 540 1-day-old male chicks (Ross 308) were used, and they were allotted into three experimental treatment groups according to their body weight (BW; initial BW: $40.1 \mathrm{~g}$ ). Each treatment had six replicates with 30 chicks per pen. The dietary treatments consisted of CON (basal diet), BAM (10 mg/kg of bambermycinsupplemented diet), and SPL $(10 \mathrm{mg} / \mathrm{kg}$ SPL supplemented diet). The feed composition is shown in Table 1 , and the feed and SPL were supported by EASY BIO Inc. (Seoul, Republic of Korea). Birds freely accessed feed and water during the experiment, and their BW and feed intake were measured at the end of each phase (Phase 1: $\mathrm{d}$ 0-10; phase 2: $\mathrm{d}$ 11-20; phase 3: $\mathrm{d} 21-35)$ after $8 \mathrm{~h}$ of feed deprivation to calculate average daily gain (ADG), average daily feed intake (ADFI), and feed efficiency (FE). Birds were raised in a controlled experimental room with a rice hull with an average relative humidity of $60 \%$. Temperature was maintained for $3 \mathrm{~d}$ at $30^{\circ} \mathrm{C}$ and daily reduced by $0.5^{\circ} \mathrm{C}$ to $24^{\circ} \mathrm{C}$, and lightening was provided by artificial light for $24 \mathrm{~h} / \mathrm{d}$.

\section{Sample processing}

At the end of the experiment, 18 birds (one bird per pen, randomly selected) were sacrificed, and the weight and length of the small intestine of the birds were measured. Jejunum and cecum samples were collected, immediately frozen, and stored at $-80^{\circ} \mathrm{C}$ until further analysis. Parts of jejunum samples were fixed in $4 \%$ formalin solution for histological analysis.

\section{Next generation sequencing}

Quick-DNA $^{\mathrm{m}}$ Fecal/Soil Microbe Microprep Kit (Zymo Research, CA, USA) was used to extract total genomic DNA from the cecal samples of chicks according to the manufacturer's protocol. For the microbial community structure analysis, V3-V4 regions of $16 \mathrm{~S}$ rDNA were amplified using the following universal primer set 
Table 1 Ingredients and nutritional values of basal diets

\begin{tabular}{|c|c|c|c|}
\hline Ingredients, \% & Starter & Grower & Finisher \\
\hline Corn & 60.92 & 56.29 & 62.07 \\
\hline Soybean meal & 26.53 & 18.25 & 10.63 \\
\hline Fermented soybean meal & 5.00 & 0.00 & 0.00 \\
\hline DDGS & 0.00 & 5.00 & 5.00 \\
\hline Unpolished rice & 0.00 & 4.00 & 3.00 \\
\hline Rice bran polish & 0.00 & 1.00 & 1.50 \\
\hline Rapeseed mineral & 0.00 & 4.00 & 3.00 \\
\hline Sesameseed meal & 0.00 & 0.00 & 0.50 \\
\hline Poultry meal & 2.50 & 5.50 & 8.00 \\
\hline Animal fat & 0.00 & 1.72 & 2.00 \\
\hline L-Lysine sulfate (55\%) & 0.62 & 0.72 & 0.75 \\
\hline L-Methionine (90\%) & 0.47 & 0.35 & 0.31 \\
\hline Threonine (98\%) & 0.22 & 0.19 & 0.19 \\
\hline L-Tryptophan (99\%) & 0.01 & 0.03 & 0.03 \\
\hline Choline chloride (50\%) & 0.10 & 0.11 & 0.14 \\
\hline $\mathrm{MCP}$ & 1.54 & 1.08 & 0.81 \\
\hline Limestone & 1.45 & 1.23 & 1.55 \\
\hline Salt & 0.25 & 0.25 & 0.25 \\
\hline $\mathrm{NaHCO}_{3}$ & 0.05 & 0.05 & 0.05 \\
\hline Vitamin premix ${ }^{a}$ & 0.20 & 0.14 & 0.11 \\
\hline Mineral premix ${ }^{b}$ & 0.15 & 0.12 & 0.12 \\
\hline Total & 100.00 & 100.00 & 100.00 \\
\hline \multicolumn{4}{|l|}{ Calculated value } \\
\hline $\mathrm{ME}, \mathrm{kcal} / \mathrm{kg}$ & 2851.00 & 2945.00 & 3040.00 \\
\hline$C P, \%$ & 21.85 & 20.40 & 19.00 \\
\hline $\mathrm{Ca}, \%$ & 1.00 & 0.90 & 1.04 \\
\hline$P, \%$ & 0.77 & 0.70 & 0.64 \\
\hline Lysine, \% & 1.49 & 1.32 & 1.19 \\
\hline Methionine, \% & 0.75 & 0.62 & 0.56 \\
\hline Threonine, \% & 1.02 & 0.94 & 0.89 \\
\hline Tryptophan, \% & 0.25 & 0.23 & 0.20 \\
\hline
\end{tabular}

aprovided per kilogram of complete diet: vitamin $A, 6300 \mathrm{IU}$; vitamin $\mathrm{D}, 2,800$ $\mathrm{IU}$; vitamin $\mathrm{E}, 35 \mathrm{mg}$; vitamin $\mathrm{K}_{3}, 1.75 \mathrm{mg}$; vitamin $\mathrm{B}_{1}, 2 \mathrm{mg}$; vitamin $\mathrm{B}_{2}, 6 \mathrm{mg}$; vitamin $B_{6}, 3 \mathrm{mg}$; vitamin $B_{12}, 13 \mu \mathrm{g}$; biotin, $0.1 \mathrm{mg}$; calcium pantothenic acid, $15 \mathrm{mg}$; folic acid, $1.5 \mathrm{mg}$; niacin, $50 \mathrm{mg}$

${ }^{\mathrm{b}}$ Provided per kilogram of complete diet: $\mathrm{Mn}, 100 \mathrm{mg} ; \mathrm{Cu}, 17 \mathrm{mg} ; \mathrm{Zn}, 92 \mathrm{mg}$; $\mathrm{Fe}, 50 \mathrm{mg} ; \mathrm{l}, 1.5 \mathrm{mg}$; Co, $0.15 \mathrm{mg}$; Se, $0.3 \mathrm{mg}$

(forward 5'-CCTACGGGNGGCWGCAG-3', reverse 5' GACTACHVGGGTATCTAATCC-3'), synthesized by Integrated DNA Technologies (IDT, Singapore). PCR conditions for amplifying the V3-V4 regions of $16 \mathrm{~S}$ rDNA were as follows; 5-min initial denaturation at $98^{\circ} \mathrm{C}$, followed by 20 amplification cycles $\left(30 \mathrm{~s}\right.$ at $98^{\circ} \mathrm{C}, 30 \mathrm{~s}$ at $56^{\circ} \mathrm{C}, 1 \mathrm{~min} 30 \mathrm{~s}$ at $72^{\circ} \mathrm{C}$ ), $5 \mathrm{~min}$ final extension at $72^{\circ} \mathrm{C}$. The resulting DNA amplicons were purified using magnetic beads (TopQ XSEP MagBead, CELLMICS, USA). A second PCR was performed to attach the Illumina universal p5/p7 overhang sequence and sample-specific barcodes. Second PCR conditions were as follows; 1-min initial denaturation at $98^{\circ} \mathrm{C}$, followed by 10 amplification cycles $\left(30 \mathrm{~s}\right.$ at $98^{\circ} \mathrm{C}, 30 \mathrm{~s}$ at $60^{\circ} \mathrm{C}, 1 \mathrm{~min}$ at $72^{\circ} \mathrm{C}$ ), final extension at $72{ }^{\circ} \mathrm{C} 3 \mathrm{~min}$. The sequencing-ready libraries were purified using magnetic beads (TopQ XSEP MagBead, CELLMICS, USA). Size distribution of the sequencing ready libraries were determined using the QSep fragment analyzer (Qsep Inc., Taiwan). DNA quantification is performed using the Quit dsDNA HS assay kit (Thermo Scientific, USA). Finally, all the libraries were pooled in equimolar quantities and diluted as necessary. Sequencing was performed on the Illumina MiSeq platform (Illumina, USA) using MiSeq Reagent Kit V3 $(2 \times$ $300 \mathrm{PE}$ ) (Illumina, USA). Mock DNA libraries were prepared with the ZymoBiomics microbial community DNA standard (Zymo Research, USA) using the amplicon library preparation procedure described above and sequenced together. This control library allowed us to evaluate potential biases and errors associated with the amplification and sequencing steps. Taxonomy profiling was performed using the open software program Quantitative Insights Into Microbial Ecology (QIIME) version 1.9.0 with NCBI 16S DB and BLASTN v2.3.0 [13]. We also performed a closed-reference operational taxonomic unit picking process to assign taxonomy using NCBI 16S DB and BLASTN (v2.3.0).

\section{Gas chromatography-mass spectrometry}

The concentration of short-chain fatty acids (SCFA) in the cecum contents was determined by gas chromatography-mass spectrometry (GC-MS). Briefly, $10 \mathrm{mg}$ of cecal contents were homogenized with extraction solution consisting of $100 \mu \mathrm{L}$ of internal standard $(100 \mu \mathrm{mol} / \mathrm{L}$ crotonic acid), $100 \mu \mathrm{L}$ hydrochloric acid, and $200 \mu \mathrm{L}$ of ether. After vigorous vortexing for $10 \mathrm{~min}$, the homogenates were centrifuged at $1,000 \times g$ for $10 \mathrm{~min}$, and $80 \mu \mathrm{L}$ of supernatants were transferred into new glass vials. Aliquots were mixed with $16 \mu \mathrm{L}$ of $N$-tert-butyldimethylsilyl$N$-methyltrifluoroacetamide (MTBSTFA) and sealed tightly. The glass vials were heated at $80^{\circ} \mathrm{C}$ for $20 \mathrm{~min}$ in a water bath, and then left at room temperature for $48 \mathrm{~h}$ for derivatization. The derivatized samples were run through a 6890 N Network GC System with an HP-5MS column and $5973 \mathrm{~N}$ network mass selective detector. Pure helium was used as carrier gas and delivered at a $1.2 \mathrm{~mL} / \mathrm{min}$ flow rate. The head pressure was set at $97 \mathrm{kPa}$ with a 20:1 split. The inlet temperature was $250^{\circ} \mathrm{C}$, and the transfer line temperature was $260^{\circ} \mathrm{C}$. The temperature program was as follows: $60^{\circ} \mathrm{C}$ for $3 \mathrm{~min}, 60-120^{\circ} \mathrm{C}\left(5^{\circ} \mathrm{C}\right.$ per min), and 120 $300^{\circ} \mathrm{C}\left(20^{\circ} \mathrm{C}\right.$ per min). The run time was $30 \mathrm{~min}$, and SCFA concentrations were quantified by comparing their peak areas with standards. 


\section{Gut histological assay}

Jejunum samples, fixed in formalin, were embedded into paraffin blocks to prepare $5-\mu \mathrm{m}$ cross sections using a Rotary Microtome CUT 5062 (SLEE MAINZ, Mainz, Germany). These sections were stained with hematoxylin and eosin and Alican blue staining methods. Total 10 villi and 10 crypts were randomly selected per experimental unit. A single observer measured villus height $(\mathrm{VH})$ and crypt depth $(\mathrm{CD})$ and counted the goblet cells numbers.

\section{qRT-PCR analysis}

Total RNA from jejunum samples was extracted using Trizol $^{\circ}$ (Invitrogen, Grand Island, NY, USA) according to the manufacturer's procedure, and the concentration and purity of RNA were determined using Nanodrop spectrophotometer (Thermo Scientific, Wilmington, DE, USA). Subsequently, cDNA samples were synthesized with the High-Capacity cDNA Reverse Transcription kit (Applied Biosystems, Carlsbad, CA, USA) according to the manufacturer's instructions. Target gene expression levels were determined using RealHelix ${ }^{\text {Tn }}$ Premier qPCR kit (NanoHelix, Daejun, Korea) with a StepOnePlus Real-Time PCR System (Applied Biosystems, Carlsbad, CA, USA). Primers for the target genes are listed in Table 2, and the expression level of glyceraldehyde-3phosphate dehydrogenase (GAPDH) is used as a housekeeping gene. The $2^{-\Delta \Delta C T}$ method was used to quantify relative mRNA expression levels.

\section{Statistical analysis}

All data were analyzed using analysis of variance (ANOVA) with Statistical System 9.4 (SAS Institute, Cary, NC, USA). Significant differences between treatments were determined using Duncan's multiple-range tests and were defined at the $P<0.05$ level.

Table 2 Oligonucleotide primers used in jejunal qRT-PCR analysis $^{a}$

\begin{tabular}{lll}
\hline Gene name & Sequence (forward, reverse) & Reference \\
\hline GAPDH & 5'-GAGGGTAGTGAAGGCTGCTG-3' & {$[14]$} \\
& 5'-CCACAACACGGTTGCTGTAT-3' & \\
CLDN1 & 5'-TGGAGGATGACCAGGTGAAGA-3' & {$[15]$} \\
& 5'-CGAGCCACTCTGTTGCCATA-3' & \\
MUC2 & 5'-TTCATGATGCCTGCTCTTGTG-3' & {$[15]$} \\
& 5'-CCTGAGCCTTGGTACATTCTTGT-3' & \\
IL-6 & 5'-GACGAGGAGAAATGCCTGACG-3' & {$[16]$} \\
& 5'-CCGAGTCTGGGATGACCACTTC-3' & \\
& 5'-TCTACACAGATGAGGTCCTGCC-3' & {$[16]$} \\
& 5'-AGGTGAAGAAGCGGTGACAG-3' & \\
\hline
\end{tabular}

${ }^{a}$ Abbreviations: CLDN1 claudin-1, GAPDH glyceraldehyde-3-phosphate dehydrogenase, IL-6 interleukin-6, IL-10 interleukin-10, MUC2 mucin 2, OCLD occludin, ZO-1 zonula occludens-1

\section{Results}

\section{Growth performance}

As indicated in Table 3, birds in the BAM and SPL groups showed significantly higher $\mathrm{BW}$ and $\mathrm{ADG}$ $(P<0.05)$ compared to those in the CON group. There were no significant differences in average feed intake between treatments, however, feed efficiency was significantly higher $(P<0.05)$ in the BAM group compared to CON group.

\section{Intestinal microbial population}

Dietary BAM and SPL supplementation significantly increased ACE and Chao 1 indexes compared to CON group $(P<0.05)$, however, Shannon and Simpson indexes were not different among treatments (Fig. 1a-d). Cecal microbial communities of BAM and SPL groups were partially and completely separated from that of CON group (Fig. 1e).

At phylum level, dietary SPL supplementation increased Firmicutes population and decreased Bacteroidetes population (Fig. 2a). Additionally, dietary SPL supplementation significantly increased $(P<0.05)$ the genus level of Lactobacillus and decreased $(P<0.05)$ that of Streptococcs (Fig. 2b). At the species level, dietary SPL supplementation significantly increased $(P<0.05)$ the populations of Lactobacillus helveticus and Lactobacillus salivarius in the SPL group compared to their populations in the CON group (Fig. 2c), and the SPL group also showed a significantly higher $(P<0.05)$ level of Akkermansia muciniphila compared to the other treatment groups (Fig. 2d). The population of the Streptococcus gallolyticus group was significantly decreased $(P<0.05)$ by dietary BAM and SPL supplementation (Fig. 2e).

Table 3 Effects of sophorolipid on growth performance of broilers ${ }^{1,2,3}$

\begin{tabular}{llllll}
\hline Treatment & CON & BAM & SPL & SEM & $P$-value \\
\hline Initial BW, g & 40.16 & 40.12 & 40.19 & 0.045 & 0.853 \\
Final BW, g & $1911.8^{\mathrm{b}}$ & $2011.6^{\mathrm{a}}$ & $2010.3^{\mathrm{a}}$ & 18.587 & 0.035 \\
ADG, g/d & $53.48^{\mathrm{b}}$ & $56.33^{\mathrm{a}}$ & $56.29^{\mathrm{a}}$ & 0.531 & 0.035 \\
ADFl, g/d & 88.62 & 87.89 & 90.45 & 0.719 & 0.344 \\
FE & $0.60^{\mathrm{b}}$ & $0.64^{\mathrm{a}}$ & $0.62^{\mathrm{ab}}$ & 0.014 & 0.010 \\
\hline
\end{tabular}

${ }^{1}$ Treatments: CON, control group fed with basal diet; BAM, group fed with 10 $\mathrm{mg} / \mathrm{kg}$ of bambermycin supplemented diet; SPL, group fed with $10 \mathrm{mg} / \mathrm{kg}$ of sophorolipid supplemented diet

${ }^{2}$ Abbreviations: $A D F I$ average daily feed intake, $A D G$ average daily gain, $B W$ body weight, $F E$ feed efficiency, SEM standard error of means

${ }^{3} \mathrm{~A}$ pen is an experimental unit; 6 replications (pens) per treatment; 30 chicks per pen

a, b Mean values within a row have different superscript letters were significantly different $(P<0.05)$ 


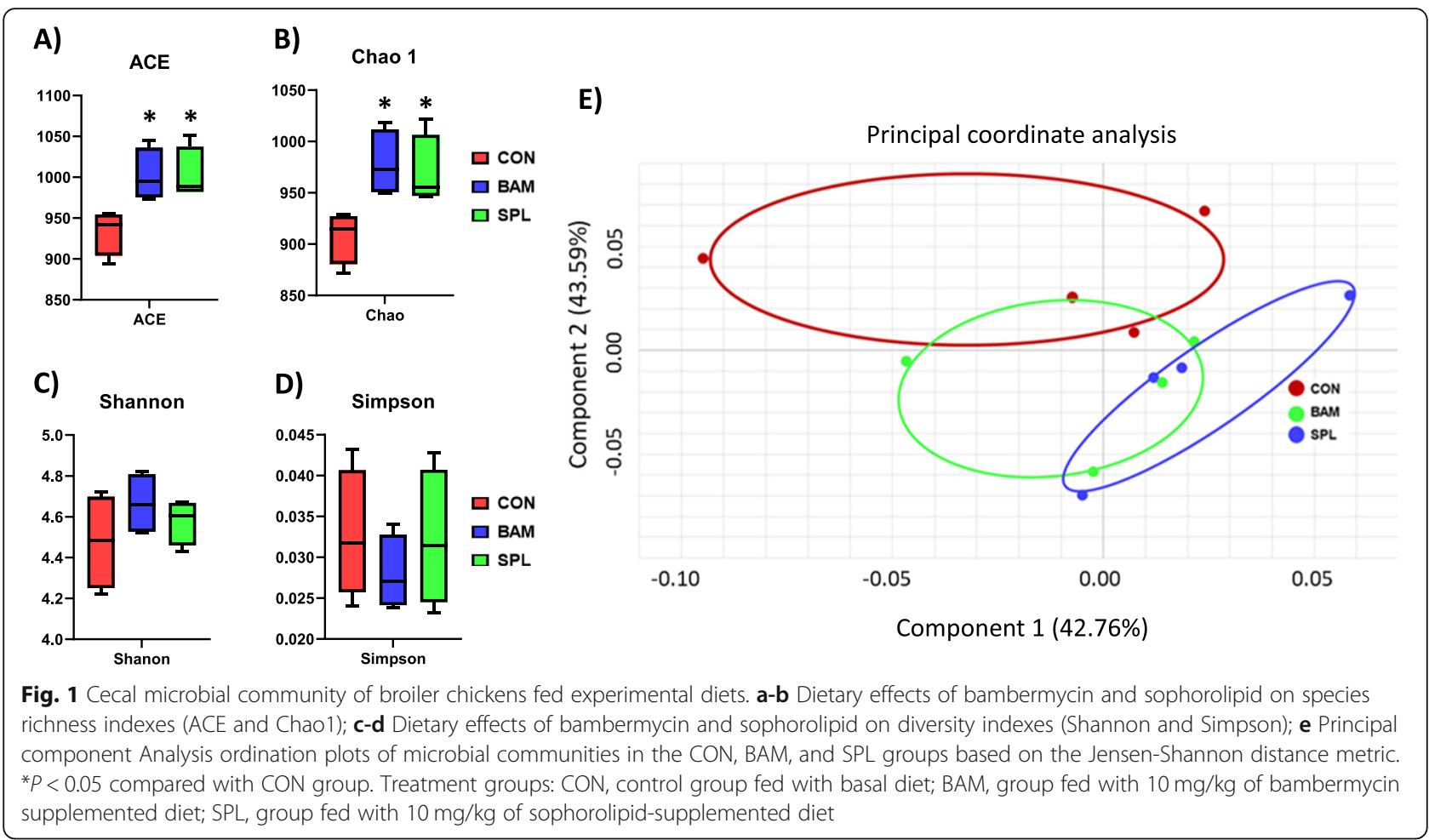

\section{Cecal short-chain fatty acid concentration}

As listed in Table 4, dietary SPL supplementation significantly increased $(P<0.05)$ the total concentration of SCFA, and those of acetate and butyrate in the SPL group compared to that in the BAM group. In addition, the ratio of propionate was significantly lowered $(P<0.05)$ in SPL group compared to BAM group.

\section{Intestinal characteristics and histological analysis}

As shown in Table 5, birds fed with the SPLsupplemented diet (SPL group) showed significantly reduced $(P<0.05)$ intestinal weight compared to those of the other treatment groups; however, gut weight per length was not changed by SPL supplementation. Hence, dietary SPL supplementation significantly
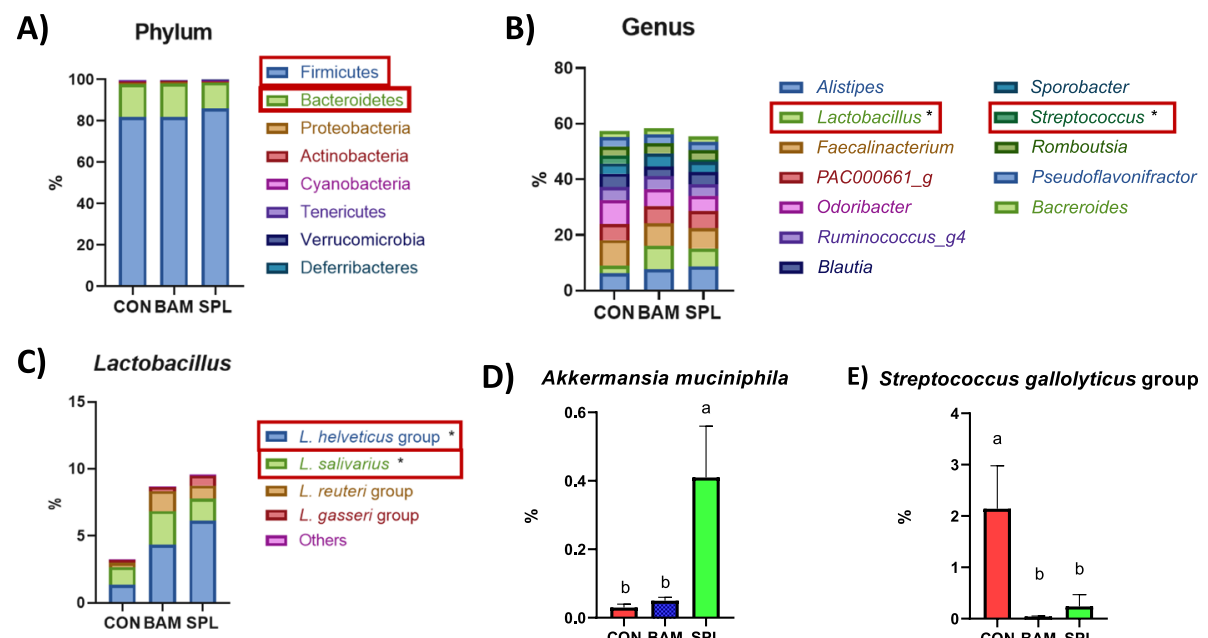

D)
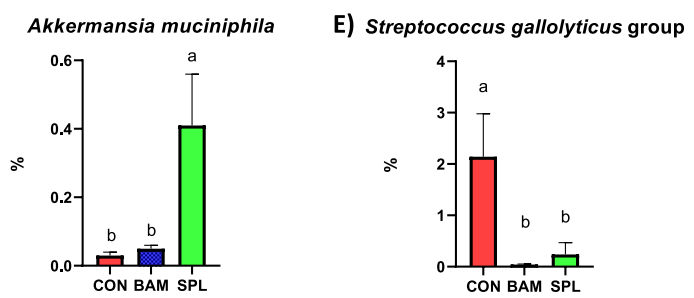

Fig. 2 Gut microbiota population of broilers fed with experimental diets. a Intestinal microflora at phylum; $\mathbf{b}$ Intestinal microflora at genus level; b-d Specific bacterial populations at the species level in the cecum of birds (Lactobacillus family, Akkermansia muciniphila, and Streptococcus gallolyticus group). ${ }^{*} P<0.05$ compared with CON group. ${ }^{a}$, b Mean values within a row have different superscript letters were significantly different $(P<0.05)$. Treatment groups: CON, control group fed with basal diet; BAM, group fed with $10 \mathrm{mg} / \mathrm{kg}$ of bambermycin supplemented diet; SPL, group fed with $10 \mathrm{mg} / \mathrm{kg}$ of sophorolipid-supplemented diet 


\section{Gene expression levels in jejunum}

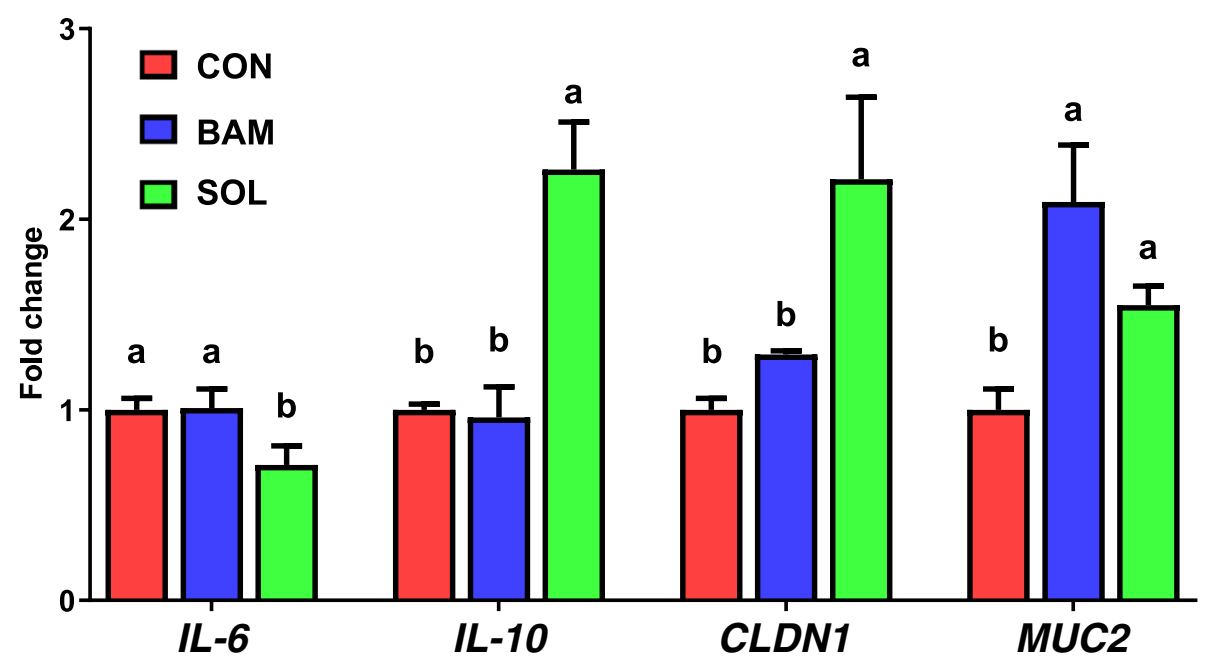

Fig. 3 mRNA expression levels of genes related to inflammation, tight junction, and mucin in the jejunum of birds fed with experimental diets. ${ }^{a}$ ${ }^{b}$ Mean values within a row have different superscript letters were significantly different $(P<0.05)$. Treatment groups: CON, control group fed with basal diet; BAM, group fed with $10 \mathrm{mg} / \mathrm{kg}$ of bambermycin supplemented diet; SPL, group fed with $10 \mathrm{mg} / \mathrm{kg}$ of sophorolipid-supplemented diet. Abbreviations: IL-6, interleukin-6; IL-10, interleukin-10; CLDN1, claudin-1; MUC2, mucin 2

increased $(P<0.05) \mathrm{VH}$ compared to that of birds in the other treatment groups without affecting $C D$ (Table 5). The ratio of $\mathrm{VH}$ to $\mathrm{CD}$ in the birds fed with the SPL-supplemented diet was the highest $(P<$ $0.05)$ compared to that of birds in CON group. Moreover, the goblet cell numbers per $1 \mu \mathrm{m}$ of villus were

Table 4 Effects of sophorolipid on cecal SCFA concentration of broilers ${ }^{1,2,3}$

\begin{tabular}{|c|c|c|c|c|c|}
\hline Treatment & CON & BAM & SPL & SEM & $P$-value \\
\hline \multicolumn{6}{|c|}{ Absolute concentration of SCFA, $\mu \mathrm{mol} / \mathrm{g}$} \\
\hline Total SCFA & $226.43^{\mathrm{a}}$ & $179.47^{b}$ & $249.61^{\mathrm{a}}$ & 10.802 & 0.012 \\
\hline Acetate & $185.91^{\mathrm{a}}$ & $143.14^{\mathrm{b}}$ & $206.06^{a}$ & 9.984 & 0.017 \\
\hline Propionate & 17.62 & 15.73 & 17.18 & 0.676 & 0.526 \\
\hline iso-butyrate & 3.69 & 3.84 & 4.01 & 0.208 & 0.850 \\
\hline Butyrate & $19.20^{\mathrm{ab}}$ & $16.76^{\mathrm{b}}$ & $22.36^{a}$ & 0.978 & 0.049 \\
\hline \multicolumn{6}{|c|}{ Percentage of SCFA, \% } \\
\hline Acetate & 82.11 & 78.98 & 82.48 & 0.852 & 0.187 \\
\hline Propionate & $7.76^{\mathrm{ab}}$ & $8.91^{\mathrm{a}}$ & $6.88^{\mathrm{b}}$ & 0.322 & 0.021 \\
\hline iso-butyrate & 1.66 & 2.17 & 1.60 & 0.130 & 0.140 \\
\hline Butyrate & 8.47 & 9.95 & 9.04 & 0.615 & 0.647 \\
\hline
\end{tabular}

${ }^{1}$ Treatments: CON, control group fed with basal diet; BAM, group fed with 10 $\mathrm{mg} / \mathrm{kg}$ of bambermycin supplemented diet; SPL, group fed with $10 \mathrm{mg} / \mathrm{kg}$ of sophorolipid supplemented diet

${ }^{2}$ Abbreviations: SCFA short-chain fatty acid, SEM standard error of means

${ }^{3} \mathrm{~A}$ chick is an experimental unit; 6 replications per treatment

$\mathrm{a}, \mathrm{b}$ Mean values within a row have different superscript letters were significantly different $(P<0.05)$ also significantly increased $(P<0.05)$ in the SPL treatment group compared to that in the other groups.

Gene expression levels related to inflammation, tight junction, and mucin secretion

As presented in Fig. 3, dietary SPL supplementation significantly downregulated $(P<0.05)$ the expression level of interleukin-6 $(I L-6)$ and upregulated $(P<0.05)$ that of interleukin-10 (IL-10) compared to the other treatments. The expression level of claudin-1 (CLDN1) significantly increased $(P<0.05)$ in the SPL group compared to the other groups. Moreover, the BAM and SPL groups showed significantly increased $(P<0.05)$ expression level of mucin 2 (MUC2) compared to the CON group.

\section{Discussion}

First, the results of this study indicated that SPL could accelerate the growth of broilers as much as bambermycin, which is in agreement with the reports of Boontiam et al. [17] which demonstrated that surfactant supplementation with a low energy and crude protein diet could improve average daily gain and feed efficiency during the overall experimental period without affecting average daily feed intake. Furthermore, both glycolipidtype antibiotics and biosurfactant increased the beneficial microbiota L. heliveticus and L. salivarius and decreased the pathogenic bacteria S. gallolyticus. In accordance with our results, Abu Hafsa and Ibrahim [18] also demonstrated that similar modulation of gut microbiota (increased Lactobacillus and decreased 
Table 5 Effects of sophorolipid on gut characteristic and histological analysis of broilers ${ }^{1,2,3}$

\begin{tabular}{|c|c|c|c|c|c|}
\hline Treatment & CON & BAM & SPL & SEM & $P$-value \\
\hline Intestinal, g/100 g body weight & $3.18^{\mathrm{a}}$ & $3.08^{\mathrm{ab}}$ & $2.96^{\mathrm{b}}$ & 0.037 & 0.038 \\
\hline Intestinal weight/length, $\mathrm{g} / \mathrm{m}$ & 30.60 & 31.12 & 30.54 & 0.319 & 0.735 \\
\hline Villus height, $\mu \mathrm{m}$ & $371.27^{\mathrm{b}}$ & $398.17^{\mathrm{ab}}$ & $422.50^{\mathrm{a}}$ & 7.483 & 0.010 \\
\hline Crypt depth, $\mu \mathrm{m}$ & 110.58 & 104.40 & 105.50 & 1.366 & 0.142 \\
\hline Villus height/crypt depth & $3.37^{b}$ & $3.82^{\mathrm{a}}$ & $4.01^{\mathrm{a}}$ & 0.099 & 0.013 \\
\hline Goblet cells/villus height, / $\mu \mathrm{m}$ & $0.22^{\mathrm{b}}$ & $0.21^{b}$ & $0.34^{\mathrm{a}}$ & 0.016 & $<0.001$ \\
\hline
\end{tabular}

${ }^{1}$ Treatments: CON, control group fed with basal diet; BAM, group fed with $10 \mathrm{mg} / \mathrm{kg}$ of bambermycin supplemented diet; SPL, group fed with $10 \mathrm{mg} / \mathrm{kg}$ of sophorolipid supplemented diet

${ }^{2}$ Abbreviation: SEM standard error of means

${ }^{3} \mathrm{~A}$ chick is an experimental unit; 6 replications per treatment

a, $b$ Mean values within a row have different superscript letters were significantly different $(P<0.05)$

Sterptococcus) by dietary probiotic supplementation significantly improved the growth of birds. Various reports related Lacobacillus species have suggested that L. heliveticus is known as the beneficial microbes in bone and mental health and L. salivarius has a positive relationship with growth of birds [19-21]. Collectively, microflora communities modulated by bambermycin and SPL were similar, however SPL have seemed to accelerate the shift of the community compared to that of bambermycin. Also, these results suggested that this microbial shift has a potential to improve the growth and health of birds by modulation of their metabolites.

On the other hand, SCFA are the main metabolites of microbial fermentation, and they have been widely studied to elucidate the specific mechanism of antibiotic growth promoter linking the host and its intestinal microbiota [22]. In 2019, Guinan et al. demonstrated that water supply with antibiotic could downregulated the SCFA concentration in cecal contents by increased colonization of Candida albicans [23]. In agreement with this study, the results of our study demonstrated that dietary bambermycin supplementation significantly reduced the concentration of total SCFA compared to birds fed control diet and SPL supplemented diet. Additionally, both acetate and butyrate were increased in the SPL group than BAM group, which might be due to the increased populations of butyrateproducing bacteria, $L$. helveticus and mucin-degrading bacteria, A. muciniphila [24, 25]. An in vitro study with $L$. helveticus showed that this probiotics strain significantly increased butyrate concentration, and it may be due to the upregulated conversion ratio of lactate to butyrate by lactating-utilizing bacteria [26]. And A. muciniphila supplemented with mucin could produce acetate and ethanol from mucin fermentation [27]. Collectively, these results suggest that dietary SPL treatment maintain the cecal SCFA concentration by intestinal colonization of SCFA-producing bacteria unlike bambermycin supplementation.
The gastrointestinal tract is the main region that plays a role in a protective system because it is the first organ to meet external substances with a large contact area [28]. Hence, the gut defense strategy employs various physiological factors (e.g., mucus barrier, tight junctions, and immune cytokines) to maintain the intestinal homeostatic balance [29]. Our results suggest that dietary SPL supplementation could enhance mucinpresenting capacity and villus turnover balance by increasing beneficial bacterial populations. At phylum level, there were higher portion of Firmicutes, and lower that of Bacteroidetes in SPL treatment group compared to the other groups. Bacteroides, known as the LPSgenerating bacteria group when they are lysed, may play a critical role to destruct intestinal integrity and morphology by lowering intestinal permeability [30], resulted in the lower Firmicutes/Bacteroidetes ratio is considered as the favorable index of weight loss [31]. At species level, Akkermansia muciniphila, has received attention because of its specific biological properties including immune modulation, wound healing, and SCFA production [32]. Moreover, various studies have demonstrated that A. muciniphila has the potential to act as a probiotic because it could exert a glucose-lowering effect by regulating gut barrier integrity through increased expression levels of tight junction proteins [33, 34]. Similar to the results of these studies, we also found an increased population of $A$. muciniphila and strengthened gut epithelial integrity and mucus secretion capacity.

Additionally, our results demonstrated that SPL could relieve the local gut immune response and strengthen the intestinal epithelial barrier by modulating the gut microbiota population. S. gallolyticus, a gram-positive pathogenic bacterium, which is commonly found in various animals and humans, and it is a potential transmission bacterium with antibiotic resistance $[35,36]$. In addition, $\mathrm{Li}$ et al. [37] demonstrated that inoculation of $S$. gallolyticus in duckling induced macrophage necroptosis in spleens by bacterial infection and increased the 
expression levels of $I L-6$, and that decreased population of $S$. gallolyticus achieved in response to dietary oregano powder has a negative relationship with the increase of anti-inflammatory cytokine $I L-10$ [38]. In accordance with the results of these previous studies, decreased population of pathogenic bacteria ( $S$. gallolyticus) by sophorolipid supplementation has the potential to alleviate immune responses by improving pro- $(I L-6)$ and anti-inflammatory $(I L-10)$ cytokine production. On the other hands, our results also found that the higher population of Lactobacillus genus in BAM and SPL groups compared to CON group. Lactobacillus is the genera of gram positive and facultative anaerobes and it can inhibit the pathogen growth by establishment of low $\mathrm{pH}$ environment through lactic acid producing capacity [39]. Therefore, our results demonstrated that microbial shift by SPL might be able to modulate immune response in broilers' intestine.

\section{Conclusions}

Dietary sophorolipid supplementation in broiler feed could modulate the intestinal microbiota population and short-chain fatty acid levels. Hence, the promoted gut environment could improve gut defense integrity, including intensified mucus layer and tight junction, and alleviate local inflammation, resulting in the acceleration of chick growth. Further studies are required to elucidate the precise relationship between sophorolipids and their effects on intestinal health.

\begin{abstract}
Abbreviations
ADFI: Average daily feed intake; ADG: Average daily gain; ANOVA: Analysis of variations; BW: Body weight; CD: Crypt depth; CLDN1: Claudin-1; FE: Feed efficiency; GAPDH: Glyceraldehyde 3-phosphate dehydrogenase; GC-MS: Gas chromatography-mass spectrometry; IL-6: Interleukin-6; IL-10: Interleukin-10; MTBSTFA: N-tert-butyldimethylsilyl-N-methyltrifluoroacetamide ; MUC2: Mucin 2; QIIME: Quantitative Insights Into Microbial Ecology; SPL: Sophorolipid; SCFA: Short-chain fatty acid; VH: Villus height
\end{abstract}

\section{Acknowledgements}

Not applicable.

\section{Authors' contributions}

MJK, MYP, JGK and KYW conceived and designed the experiments; MJK and MYP mainly performed the experiments; MJK and YSC analyzed the data; JC, DP, HBL and IGC contributed reagents/materials/analysis tools; MJK wrote the manuscript. All authors read and approved the final manuscript.

\section{Funding}

This work was financially supported by EASYBIO Inc. and Korea University.

\section{Availability of data and materials}

Not applicable.

\section{Declarations}

\section{Ethics approval}

All of works related to animal was conducted in accordance with the guidelines and regulations for the care and the use of experimental animals was approved by the Korea University Institutional Animal Care \& Use Committee (Permission No. KUIACUC-2020-0097).
Consent for publication

Not applicable.

\section{Competing interests}

The authors declare that they have no conflict of interest.

\section{Author details}

'Department of Biotechnology, Korea University, 145 Anam-ro, Seoul 02841, Republic of Korea. ${ }^{2}$ Pathway Intermediates, Seoul 02841, Republic of Korea.

Received: 12 January 2021 Accepted: 13 May 2021

Published online: 12 July 2021

\section{References}

1. Danzeisen JL, Kim HB, Isaacson RE, Tu ZJ, Johnson TJ. Modulations of the chicken cecal microbiome and metagenome in response to anticoccidial and growth promoter treatment. PLoS One. 2011;6(11):e27949. https://doi. org/10.1371/journal.pone.0027949.

2. Bates J, Jordens JZ, Griffiths DT. Farm animals as a putative reservoir for vancomycin-resistant enterococcal infection in man. J Antibicrob Chemother. 1994;34(4):507-14. https://doi.org/10.1093/jac/34.4.507.

3. Munk P, Knudsen BE, Lukjacenko O, Duarte ASR, Luiken RE, Van Gompel L, et al. Abundance and diversity of the fecal resistome in slaughter pigs and broilers in nine European countries. Nature. 2017;3:898-908.

4. Wang JP, Lee JH, Yoo JS, Cho JH, Kim HJ, Kim IH. Effects of phenyllactic acid on growth performance, intestinal microbiota, relative organ weight, blood characteristics, and meat quality of broiler chicks. Poult Sci. 2010;89(7):154955. https://doi.org/10.3382/ps.2009-00235.

5. Roy A, Haldar S, Mondal S, Ghosh TP. Effects of supplemental exogenous emulsifier on performance, nutrient metabolism, and serum lipid profile in broiler chickens. Vet Med Int. 2010;11:262604.

6. Chen C, Jung B, Kim WK. Effects of lysophospholipid on growth performance, carcass yield, intestinal development, and bone quality in broilers. Poult Sci. 2019;98(9):3902-23. https://doi.org/10.3382/ps/pez111.

7. Cho KJ, Kim YB, Kim EK. Production and application of sophorolipid, a microbial surfactant. Korean Soc Biotechnol Bioeng J. 1999;14:747-53.

8. Develter DW, Lauryssen LM. Properties and industrial applications of sophorolipid. Eur J Lipid Sci Technol. 2010;112(6):628-38. https://doi.org/10.1 002/ejlt.200900153.

9. Borsaniyiova M, Patil A, Mukherji R, Prabhune A, Bopegamage S. Biological activity of sophorolipids and their possible use as antiviral agents. Folia Microbiol. 2016;61(1):85-9. https://doi.org/10.1007/s12223-015-0413-z.

10. Kwak MJ, Park MY, Kim J, Lee H, Whang KY. Curative effects of sophorolipid on physical wounds: in vitro and in vivo studies. Vet Med Sci. 2021;00:1-9. https://doi.org/10.1002/vms3.481.

11. Hardin R, Pierre J, Schulze R, Mueller CM, Fu SL, Wallner SR, et al. Sophorolipids improve sepsis survival: effects of dosing and derivatives. J Surg Res. 2008;142:314-9.

12. Concaix FB. Use of sophorolipids comprising diacetyl lactones as agent for stimulating skin fibroblast metabolism. U S Patent No 6,596,265. 2003.

13. Yoon SH, Ha SM, Kwon S, Lim J, Kim Y, Seo H, et al. Introducing EzBioCloud: a taxonomically united database of $16 \mathrm{~S}$ rRNA and whole genome assemblies. Int J Syst Evol Microbiol. 2017;67(5):1613-7. https://doi.org/10.1 099/ijsem.0.001755.

14. Li X, McFarland DC, Velleman SG. Effect of Smad3-mediated transforming growth factor- $\beta 1$ signaling on satellite cell proliferation and differentiation in chickens. Poult Sci. 2008;87(9):1823-33. https://doi.org/10.3382/ps.200800133.

15. Song B, Li H, Wu Y, Zhen W, Wang Z, Xia Z, et al. Effect of microencapsulated sodium butyrate dietary supplementation on growth performance and intestinal barrier function of broiler chickens infected with necrotic enteritis. Anim Feed Sci Technol. 2017;232:6-15. https://doi.org/10.1 016/j.anifeedsci.2017.07.009.

16. Heidari M, Wang D, Delekta P, Sun S. Marek's disease virus immunosuppression alters host cellular reponses and immune gene expression in the skin of infected chickens. Vet Immunol Immunopathol. 2016;180:21-8. https://doi.org/10.1016/j.vetimm.2016.08.013.

17. Boontiam W, Hyun YK, Jung B, Kim YY. Effects of lysophospholipid supplementation to reduced energy, crude protein, and amino acid diets on growth performance, nutrient digestibility, and blood profiles in broiler chickens. Poult Sci. 2019;98(12):6693-701. https://doi.org/10.3382/ps/pex005. 
18. Abu Hafsa SH, Ibrahim SA. Effect of dietary polyphenol-rich grape seed on growth performance, antioxidant capacity and ileal microflora in broiler chicks. J Anim Physiol Anim Nutr. 2018;102(1):268-75. https://doi.org/1 $0.1111 /$ jpn.12688.

19. Ohland CL, Kish L, Bell H, Thiesen A, Hotte N, Pankiv E, et al. Effects of Lactobacillus helveticus on murine behavior are dependent on diet and genotype and correlate with alterations in the gut microbiome. Psychoneuroendocrinology. 2013;38(9):1738-47. https://doi.org/10.1016/j. psyneuen.2013.02.008.

20. Liang S, Wang T, Hu X, Luo J, Li W, Wu X, et al. Administration of Lactobacillus helveticus NS8 improves behavioral, cognitive, and biochemical aberrations caused by chronic restraint stress. Neuroscience. 2015;310:561-77. https://doi.org/10.1016/j.neuroscience.2015.09.033.

21. Zhu NH, Zhang RJ, Wu H, Zhang B. Effects of Lactobacillus cultures on growth performance, xanthophyll deposition, and color of the meat and skin of broilers. J Appl Poult Res. 2009;18(3):570-8. https://doi.org/10.3382/ja pr.2009-00012.

22. Le Poul E, Loison C, Struyf S, Springael JY, Lannoy V, Decobecq ME, et al. Functional characterization of human receptors for short chain fatty acids and their role in polymorphonuclear cell activation. J Biol Chem. 2003; 278(28):25481-9. https://doi.org/10.1074/jbc.M301403200.

23. Guinan J, Wang S, Hazbun TR, Yadav H, Thangamani S. Antibiotic-induced decreases in the levels of microbial-derived short-chain fatty acids correlate with increased gastrointestinal colonization of Candida albicans. Sci Rep. 2019:9:1-11.

24. Parada Venegas D, De la Fuente MK, Landskron G, González MJ, Quera R, Dijkstra G, et al. Short chain fatty acid (SCFA)-mediated gut epithelial and immune regulation and its relevance in inflammatory bowel diseases. Front Immunol. 2019;10:277-92.

25. Taverniti V, Guglielmetti S. Health-promoting properties of Lactobacillus helveticus. Front Microbiol. 2012;3:392-404.

26. Vitali B, Ndagijimana M, Maccaferri S, Blagi E, Guerzoni ME, Brigidi P. An in vitro evaluation of the effect of probiotics and prebioitcs on the metabolic profile of human microbiota. Anaerobe. 2012;18(4):386-91. https://doi.org/10.1016/j.anaerobe.2012.04.014.

27. Derrien M, Vaughan EE, Plugge CM, de Vos WM. Akkermansia muciniphila gen. nov., sp. Sp. Nov., a human intestinal mucin-degrading bacterium. Int J Syst Evol Microbiol. 2004;54:1469-76.

28. Artis D. Epithelial-cell recognition of commensal bacteria and maintenance of immune homeostasis in the gut. Nat Rev Immunol. 2008;8(6):411-20. https://doi.org/10.1038/nri2316

29. Schroeder BO. Fight them or feed them: how the intestinal mucus layer manages the gut microbiota. Gastroenterol Rep. 2019;7(1):3-12. https://doi. org/10.1093/gastro/goy052.

30. Chen $\mathrm{K}$, Zhao H, Shu L, Xing H, Wang C, Lu C, et al. Effect of resveratrol on intestinal tight junction proteins and the gut microbiome in high-fat dietfed insulin resistant mice. Int J Food Sci Nutr. 2020;71(8):965-78. https://doi. org/10.1080/09637486.2020.1754351.

31. Qu L, Liu Q, Zhang Q, Tuo X, Fan D, Deng J, et al. Kiwifruit seed oil prevents obesity by regulating inflammation, thermogenesis, and gut microbiota in high-fat diet-induced obese C57BL/6 mice. Food Chem Toxicol. 2019;125: 85-94. https://doi.org/10.1016/j.fct.2018.12.046.

32. Earley H, Lennon G, Balfe Á, Coffey JC, Winter DC, O'Connell PR. The abundance of Akkermansia muciniphila and its relationship with sulphated colonic mucins in health and ulcerative colitis. Sci Rep. 2019;9:1-9.

33. Ashrafian F, Behrouzi A. Comparative study of effect of Akkermansia muciniphila and its extracellular vesicles on toll-like receptors and tight junction. Gastroenterol Hepatol Bed Bench. 2019;12(2):163-8.

34. Su H, Mo J, Ni J, Ke H, Bao T, Xie J, et al. Andrographolide Exerts antihyperglycemic effect through strengthening intestinal barrier function and increasing microbial composition of Akkermansia muciniphila. Oxid Med Cell. 2020;6538930:1-20. https://doi.org/10.1155/2020/6538930.

35. Dumke J, Hinse D, Vollmer T, Schulz J, Knabbe C, Dreier J. Potential transmission pathways of Streptococcus gallolyticus subsp gallolyticus. PLoS One. 2015;10:e0126507.

36. Nomoto R, Le HTT, Sekizaki T, Osawa R. Antimicrobial susceptibility of Streptococcus gallolyticus isolated from humans and animals. Jpn J Infect Dis. 2013;66(4):334-6. https://doi.org/10.7883/yoken.66.334.

37. Li M, Liu B, Gu C, Zhang W, Yang J, Cheng G, et al. Necroptosis of splenic macrophages induced by Streptococcus gallolyticus subsp. pasteurianus. Avian Dis. 2017;61(1):115-22. https://doi.org/10.1637/11449-061216-Reg.
38. Bauer BW, Gangadoo S, Bajagai YS, Van TTH, Moore RJ, Stanley D. Oregano powder reduces Streptococcus and increases SCFA concentration in a mixed bacterial culture assay of chicken. PloS One. 2019;13(3):e0216853. https://doi.org/10.1371/journal.pone.0216853.

39. Rodriguez-Cebezas ME, Camuesco D, Arribas B, Garrido-Mesa N, Comalada

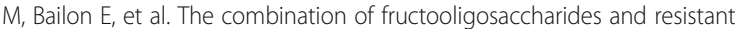
starch shows prebiotic additive effects in rats. Clin Nutr. 2010;29(6):832-9. https://doi.org/10.1016/j.clnu.2010.05.005.

\section{Ready to submit your research? Choose BMC and benefit from:}

- fast, convenient online submission

- thorough peer review by experienced researchers in your field

- rapid publication on acceptance

- support for research data, including large and complex data types

- gold Open Access which fosters wider collaboration and increased citations

- maximum visibility for your research: over $100 \mathrm{M}$ website views per year

At BMC, research is always in progress.

Learn more biomedcentral.com/submissions 